Dept. of Surgery,

Facuity of Vet. Med., Assiut Univ.,

Head of Dept. Prof. Dr. N.A. Misk.

\title{
SURGICAL APPROACH OF THE TENDON SHEATHS OF THE TARSAL REGION IN DONKEY (With 10 Figs.)
}

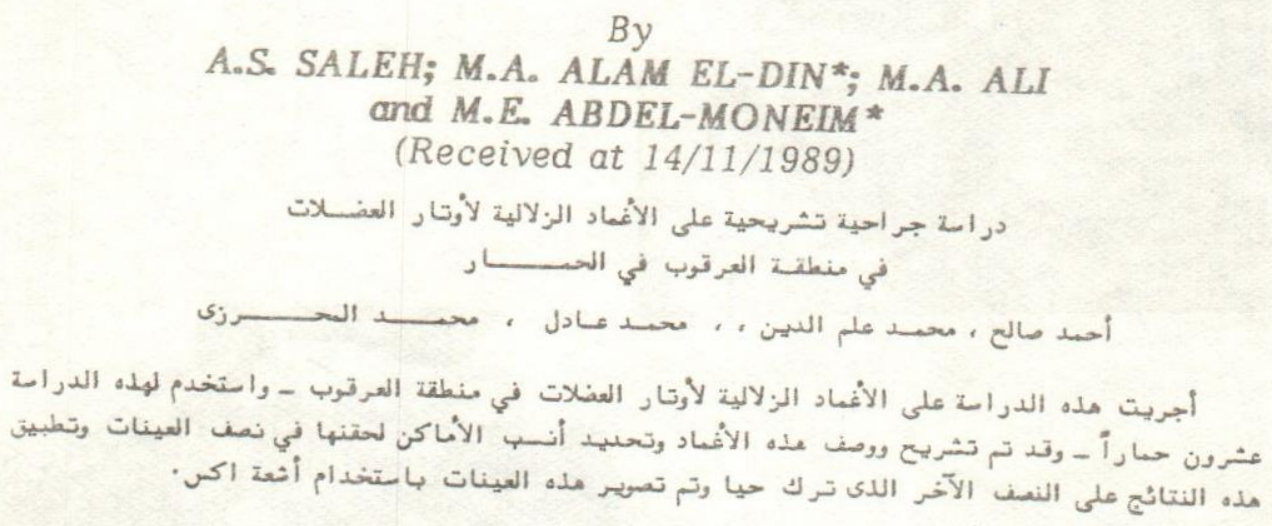

\section{SUMMARY}

The present work was carried out on the tendon sheaths of the tarsal joint in twenty donkeys. The lenght, capacity, position and relations of these sheaths were described and their sites of injection were perfectly determined. The proper sites for injection were applied in the living animals thenafter these animals were radiographed.

\section{INTRODUCTION}

Synovial sheaths may be the seat of either acute or chronic synovitis, mostly as a result of overstrain of the associated tendon. Certain anatomical sites are more likely to suffer from tendon strain injuries (WEBBON, 1973). In large animals there are no major muscle groups from the carpal and hock joints distally, for this reason tendons are relatively unprotected and can suffer a wide variety of injuries such as complete severing or rupture (TURNER, 1984).

* Dept. of Anatomy \& Histology, Faculty of Vet. Med., Assiut University. 


\section{A.S. SALEH, et al}

Tendovaginits is one of the main causes of lameness in equine (TAYLOR, 1955). Therefore, the aim of the present work is to study the tendon sheaths in the tarsal region in donkey.

\section{MATERIAL and METHODS}

Twenty donkeys were used in this study. ten of them were injected with 10\% formalin and the tarsal region joints of these animals were subjected to the anatomical study. The external landmarks were determined to assure the proper sites of injection of the tendon sheaths in this region.

The sheaths were injected by gum milk latex to facilitate its description. The tendon sheaths of the living donkeys were injected by urografin $76 \%$ and radiographed.

The nomenclature used in the present study was that adopted to N.A.V., 1983.

\section{RESULTS}

The tendon sheaths of the tarsal region in donkey are located on the dorsal and medial aspects of the tarsal joint. They are: Vag. tendineum m.extensoris digit. longi, Vag.tendinis m.extensoris digit. lateralis pedis, Vag. tendinis m. tibialis cranialis, Vag. tendinis m. flexoris digit. medialis and Vag. tendinis m. flexoris digit. laterialis.

\section{Vag tendineum $m$ extensoris digit. longi:}

The tendon sheath of the M.extensor digitorum longus $(1,3 / 1)$ is 13.4 to 16.5 $\mathrm{cm}$ in length. It begins 3.5 to $4.0 \mathrm{~cm}$ above the level of the lateral malleolus of th tibia and terminates at the proximal fourth of the large metatarsal bone. It passes on the dorsal aspect of the joint capsule of the tarsal joint medial to the dorsal pedal blood vessels thenafter the dorsal aspect of the large metatarsal bone in relation to the M.extensor digitorum brevis.

Injection of this sheath is more favourable on the dorsal aspect of the tarsal joint just medial to the lateral ridge of the trochlea of the Talus (1, 3). The needle must be directed upward and care should be taken to avoid the joint capsule and the dorsal pedal blood vessels which are closely related to the sheath.

Another site for injection of the tendon sheath of the M.extensor digitorum longus lies on the dorsal aspect of the proximal extremity of the third metatarsal bone distal to the distal anular ligament and the needle must be directed upward. However, after injection the injected material may ooze through the pore left by the needle because this site is covered by a thin layer of fascia. The maximum capacity of the sheath may reach $12.5 \mathrm{cc}$.

Assiut Vet.Med.L Vol 24, No. 47, Oct. 1990. 


\section{TARCAL TENDON SHEATHS}

\section{Vag. tendinis mextensoris digit. lateralis pedis:}

The tendon sheath of the M.extensor digitorum lateralis $(2,3 / 2)$ is 9.5 to 12 $\mathrm{cm}$ in length. It starts 3 to $4.2 \mathrm{~cm}$ above the lateral malleolus of the tibia and ends at the proximal extremity of the fourth and third metatarsal bones. The sheath descends in the groove present on the lateral malleolus of the tibia and then on the lateral collateral ligament of the tarsal joint.

The sheath is available, for injection, only on the lateral malleolus of the tibia and the needle must be directed downwards (2, 3/2). Elsewhere the tendon is concealed by the lateral collateral ligament and the dense fascia of the tarsal region. Its maximum capacity is $2 \mathrm{cc}$.

\section{Vag. tendinis motibialis cranialis:}

The tendon sheath of the M.tibialis cranialis $(4,5 / 3)$ is 4.0 to $4.5 \mathrm{~cm}$ in length. It is situated on the dorsal aspect of the tarsal joint incontact with its joint capsule. The sheath is related to the cranial tibial blood vessels and the M.extensor digitorum longus laterally and to the saphena vein medially.

Injection of the sheath of the M.tibialis cranialis is more siutable midway of the imaginary line between the two malleoli of the tibia just medial to the saphena vein. The needle must be directed upward $(4,5)$ and care should be taken to avoid the injury of the above mentioned blood vessels and the joint capsule of the tarsal joint. The maximum capacity of this sheath is $2.5 \mathrm{cc}$.

\section{Vag. tendinis m.flexoris digit. medialis:}

The tendon sheath of the M.flexor digitorum mediaiis $(6,8 / 4)$ is 16 to $17 \mathrm{~cm}$ in length. It begins 3.0 to $4.5 \mathrm{~cm}$ above the medial malleolus of the tibia and terminates 3 to $4 \mathrm{~cm}$ distal to the level of the proximal extremity of the second metatarsal bone. It passes on the medial border of the tibia thenafter in the groove which is found on the medial malleolus where it is related to the medial collateral ligament of the tarsal joint and afterthat becomes partially undercovered by it.

There are two seats for injection of this tendon sheath. The first one is found just caudal to the tibia $2 \mathrm{~cm}$ above its medial malleolus and the needle should be directed downward $(6,8)$. The second seat is situated just caudal to the proximal extremity of the second metatarsal bone and the needle must be directed upward. In the later site it must be differentiated between this tendon sheath and that of the M.flexor digitorum lateralis which lies incontact to it. Between these two sites described above the sheath could not be reached because it is deeply insinuated in the medial collateral ligament. The maximum capacity of this sheath is $3.5 \mathrm{cc}$.

Assiut VetaMed.l Yol. 24, No 47, Oct. 1990. 


\section{A.S. SALEH, et al}

\section{Vag tendinis m.flexoris digit. lateralis:}

The tendon sheath of the M.flexoris digitorum lateralis $(7,8 / 5)$ is 15.0 to $16.5 \mathrm{~cm}$ in length. It begins 3.0 to $3.5 \mathrm{~cm}$ proximal to the medial malleolus and ends 3.0 to $4.5 \mathrm{~cm}$ distal to the proximal extremity of the third metatarsal bone. It passes distally caudal to the tibia, thenafter comes in relation to the caudal aspect of the joint capsule of the tarsal joint.

The sheath can be injected $1 \mathrm{~cm}$ above the proximal extremity of the second metatarsal bone $(7,8)$ in the groove bounded medially by Sustentaculum tali, which is easily palpated, and lateraly by the tendon of the M.flexor digitorum superficialis and the plantar tarsal ligament which can also be palpated. The maximum capacity of this sheath is $12.2 \mathrm{cc}$.

Any communication between the studied tendon sheaths and the bursae or joint cavities of the tarsal joint was not recorded.

Inflammation in the tarsal region may result in adhesion of the synovial sheaths and consequently may causes partial obstruction as observed in one of the examined specimens $(9,10 / 1,2)$.

\section{DISCUSSION}

IBRAHIM (1987) mentioned that the tarsal joint in donkey has tendon sheaths on its flexor aspect, bursae on its extensor aspect and sheaths and bursae on its medial side. Similar results were given in the present work. The author added that communications between these synovial structures were not demonstrated which agrees also the present findings.

SKERRITT and MCLELLAND (1984) stated that most sheaths in the tarsal region of horse start a few centimeters proximal to the lateral malleolus and end at the proximal extremity of the large metatarsal bone. However, the sheath of the deep digital flexor tendon extends from 5 to $7 \mathrm{~cm}$ proximal to the medial malleolus to a quarter of the way down the metatarsus. These results correspond that described in the same animal by SISSON (1975) and that found in donkey as recorded in the present work.

WHEAT (1955) mentioned that in many cases of tenosynovitis of the deep flexor tendon at the hock (throughpin) it has been possible to aspirate 60 to $80 \mathrm{cc}$ of fluid from the tendon sheath. The present study investigated that each of the two heads of the deep digital flexor muscle has a separate tendon sheath, the maximum capacity of the tendon sheath of the M.flexor digitorum medialis is $3.5 \mathrm{cc}$ and that of the M.flexor digitorum lateralis is $12.2 \mathrm{cc}$ in normal condition. 


\section{TARSAL TENDON SHEATHS}

Adhesions to the surrounding tendon sheaths usually occur in domestic animals (TURNER, 1984). A similar condition was observed in the present study in which the inflammation caused partial adhesion and obstruction of the tendon sheaths ( 9 , $10 / 1,2)$.

\section{REFERENCES}

Ibrahim, M.T. (1987): Some anatomical studies on some synovial bursae in donkey. M.V.Sc. (Anatomy), Thesis, Fac. Vet. Med., Assiut University.

Nomina Anatomica Veterinaria (1983): Third edition, published by the international committe of veterinary gross anatomical nomenclature under the financial responsibility of the world association of Vet. anatomists. Ithaca. New York.

Sisson, 5. (1975): Equine myology, in Sission and Grossman's: The anatomy of the domestic animals 5th edition. Rev. by R. Getty, W.B. Saunders Company, Philadelphia. London. Toronto.

Skerritt, G.C. and J. McLelland (1984): An introduction to the functional anatomy of the limbs of the domestic animals 1st edition Wright, Bristol.

Taylor, J.A. (1955): Regional and applied anatomy of the domestic animals part I, head and neck. Edinburgh. Tweddale Court. London.

Turnur, S.A. (1984): Large animal orthopadics, in Jenning's: The practice of the large animal surgery. volume II, 1st edition W.B. Saunders Company, Philadelphia London. Toronto.

Wheat. J.D. (1955): The use of hydrocortisone in the treatment of joint and tendon disorders in large animals. J.A.V.M.A., July, 64-67.

Webbon, P.M. (1973): Equine tendon stress injuries. Equine Vet. J., 5: 58-60.

\section{LEGEND OF FIGURES}

Figs. (1 to 10): Radiographs fo the tendon sheaths of the tarsal region in donkey (left) and its sketchs (right).

1- Vag. tendineum m.extensoris digit. longi

2- Vag. tendinis m.extensoris digit. lateralis

3- Vag. tendinis $\mathrm{m}$. tibialis cranialis

4- Vag. tendinis m.flexoris digit. medialis

5- Vag. tendinis m.flexoris digit. lateralis

A, Tibia; B, Calcaneus; C, Talus; D, Os tarsi centrale; E, Ossa tarsi I \& II; F, Os tarsale III; G, Os tarsale IV; H, Os metatarsale III; I, Os metatarsale II; J, Os metatarsale IV. 
A.S. SALEH, et al.
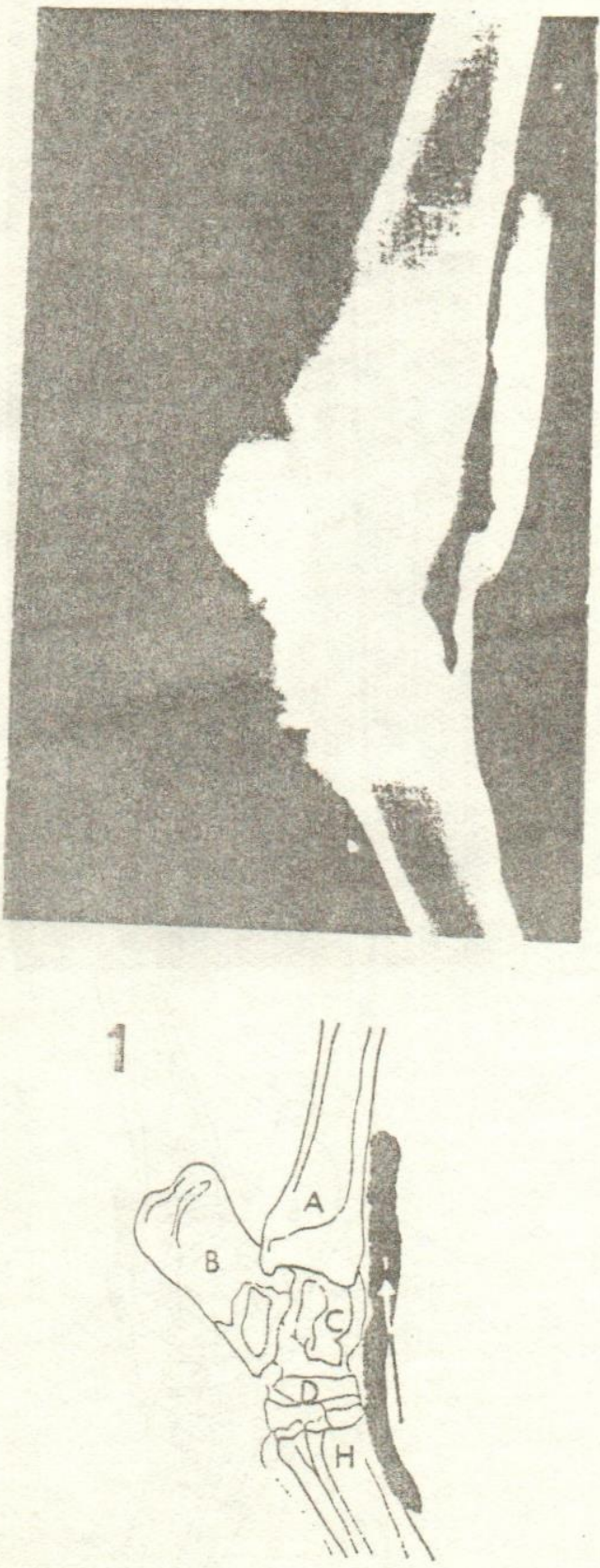

Assiut Vet.Med.L VoL 24, No. 47, Oct. 1990
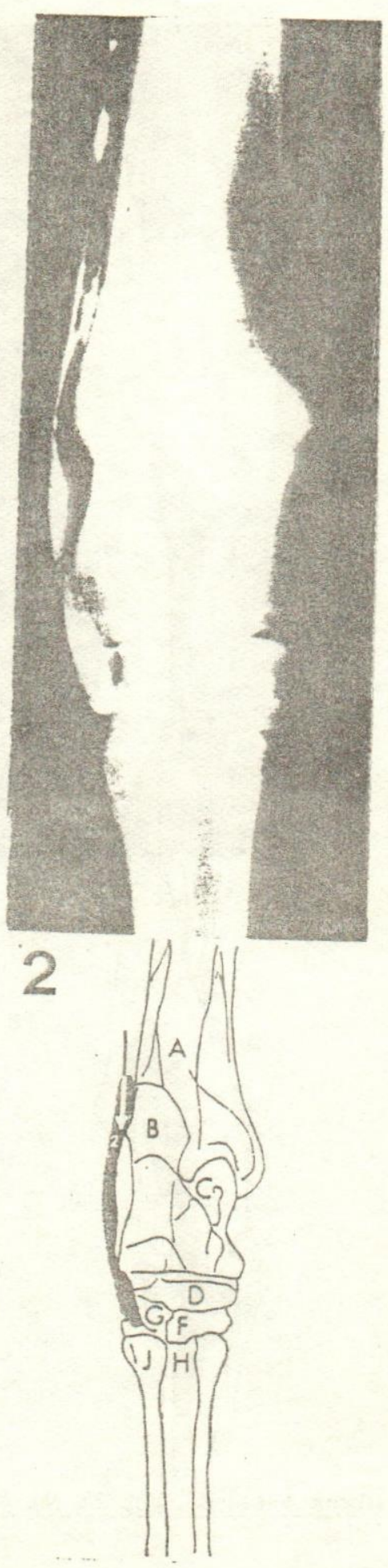
TARSAL TENDON SHEATHS

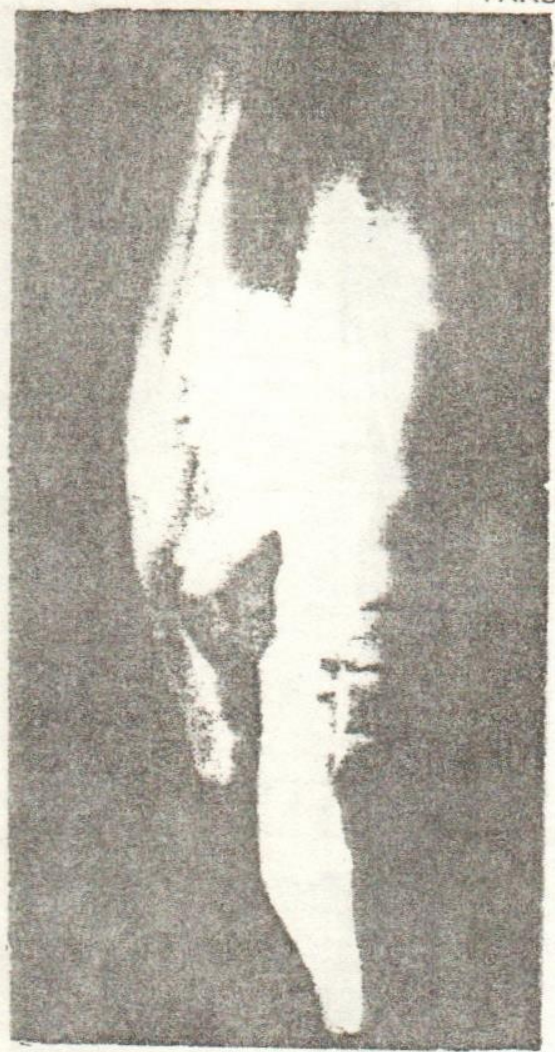

3

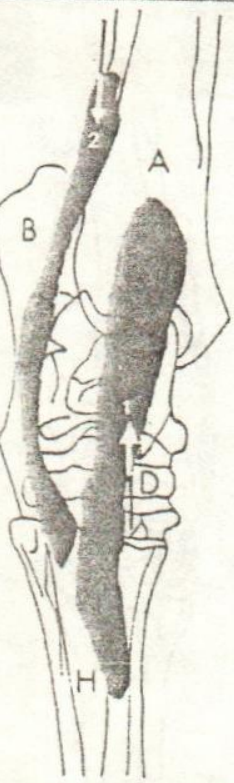

Assiut Vet_Med.J. Vol. 24, No. 47, Oct. 1990.

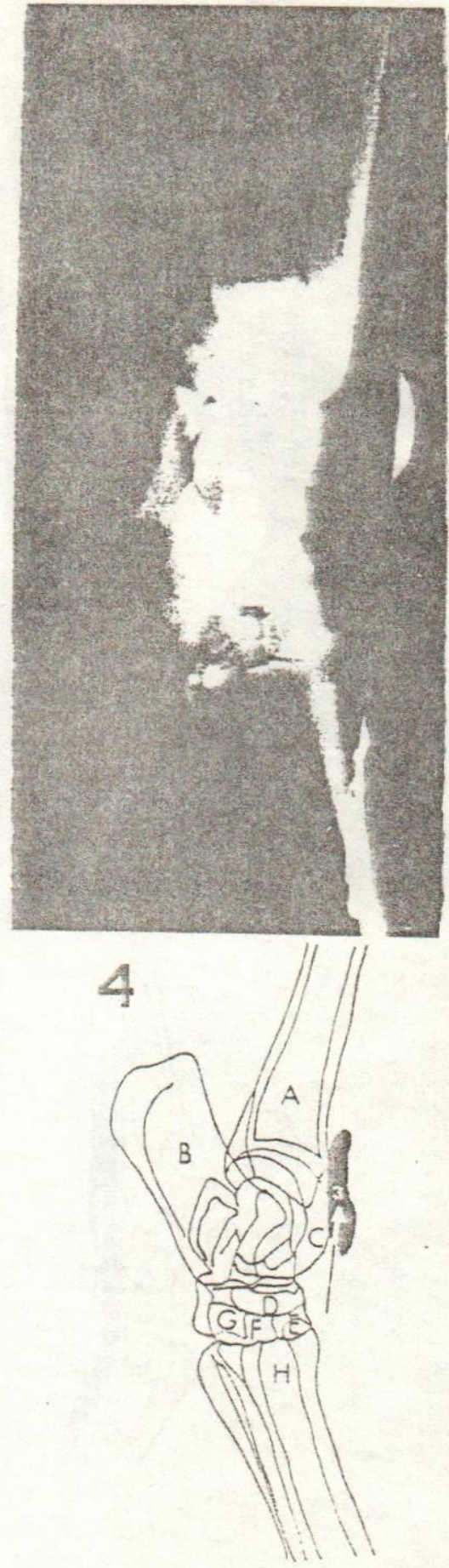


A.S. SALEH, et al
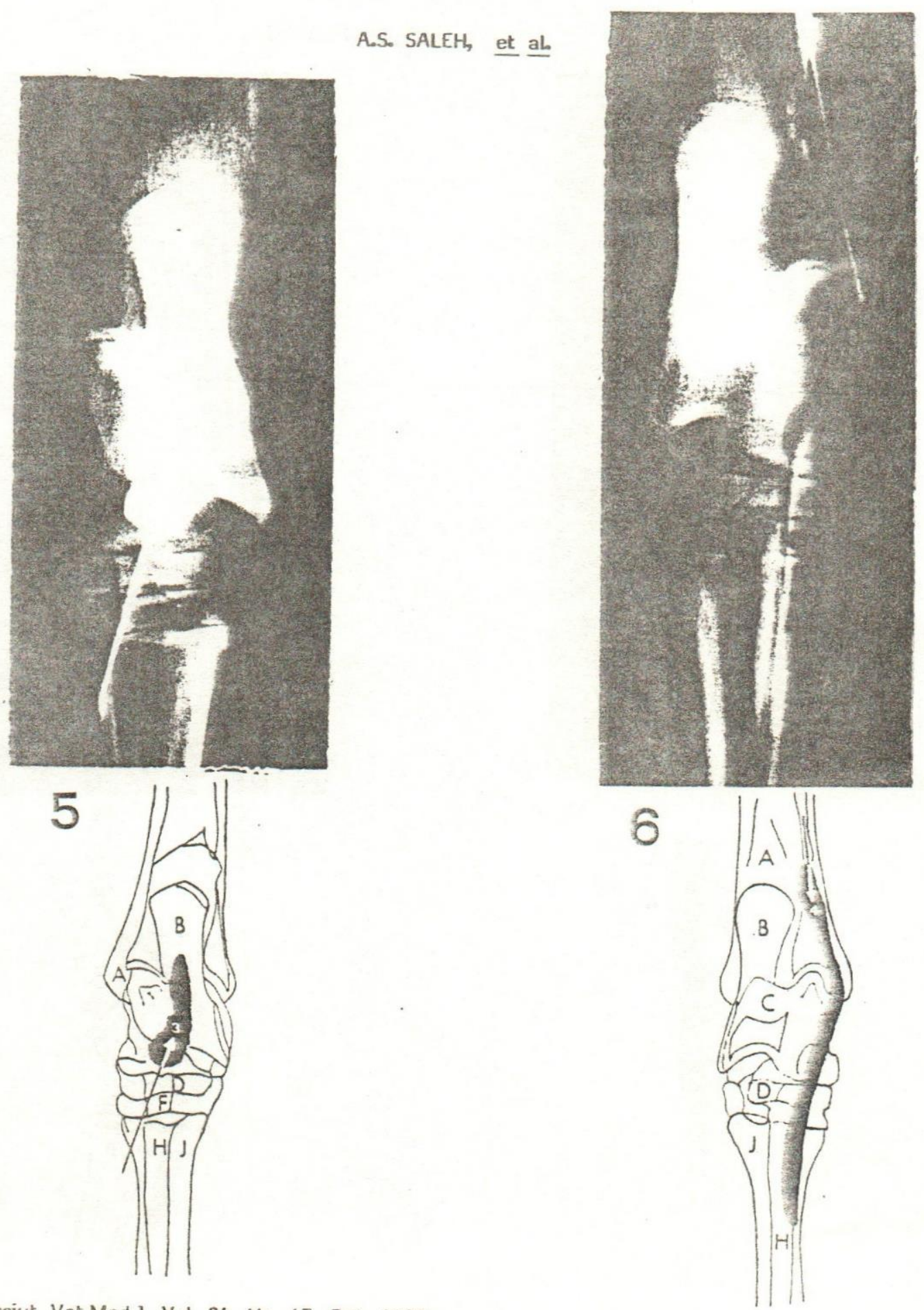

Assiut Vet.Med.1. Vol. 24, No. 47, Oct. 1990. 
TARSAL TENDON SHEATHS
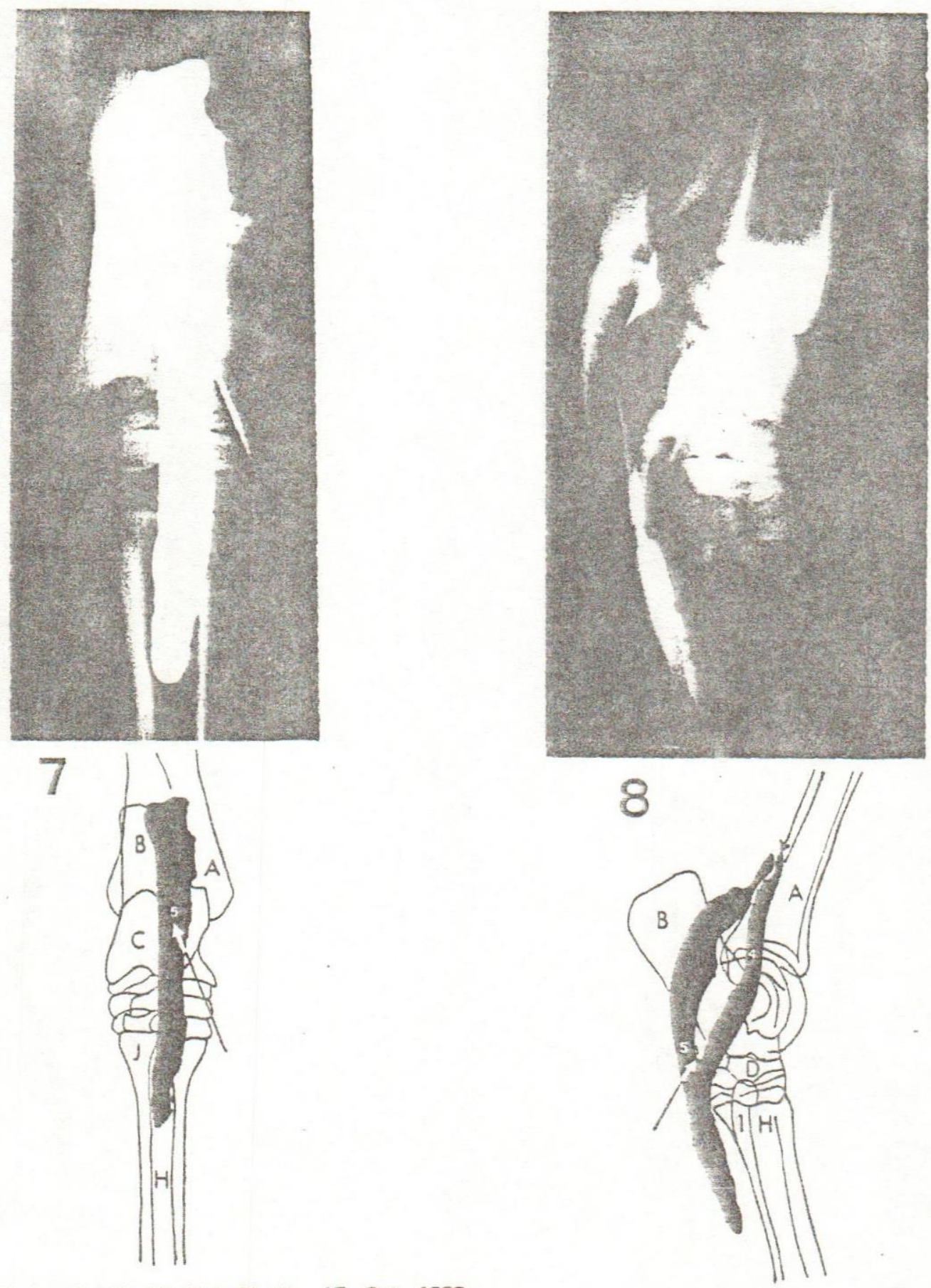

Assiut Vet.Med. bo Vol 24, No. 47, Oct, 1990. 

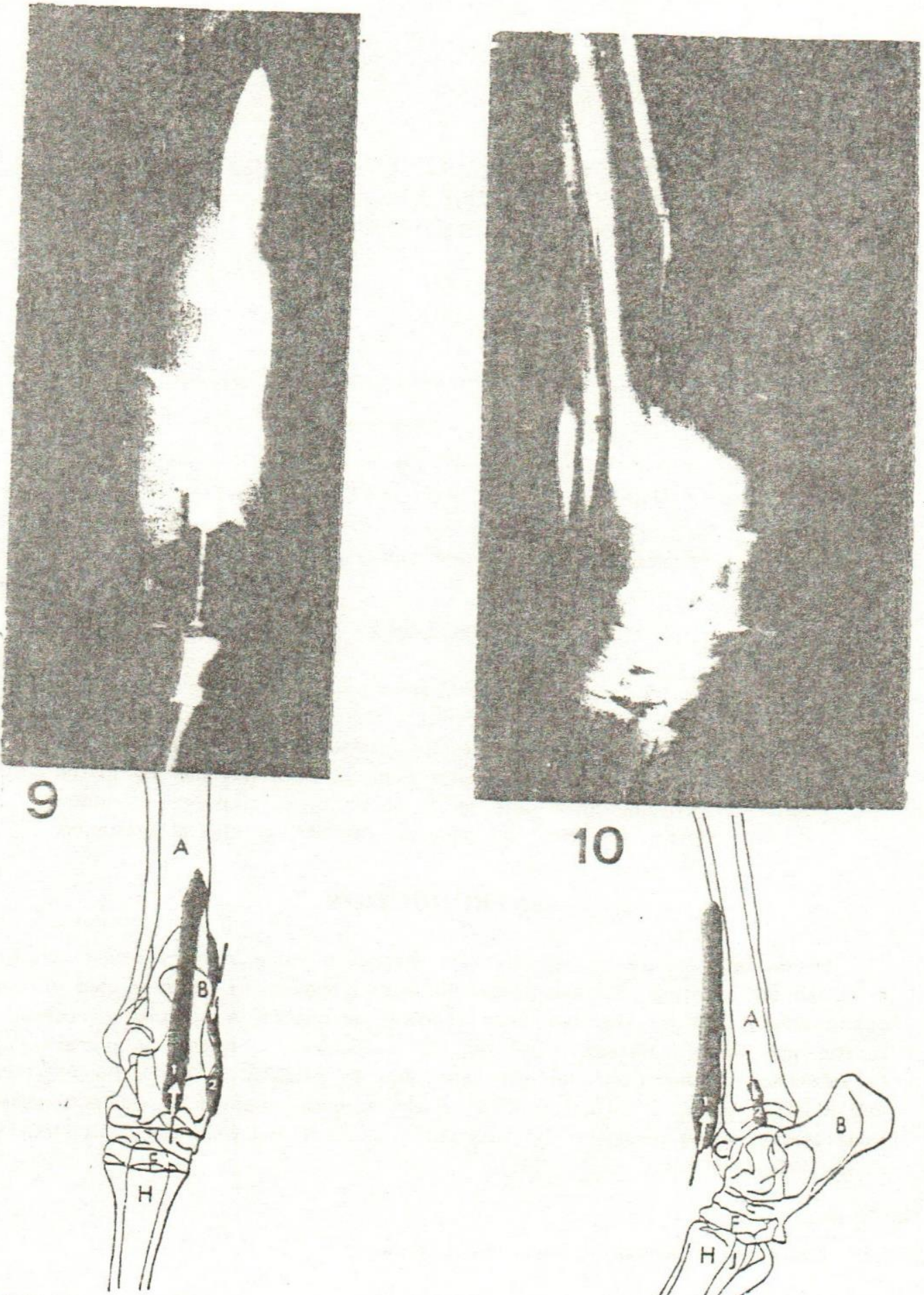

Assiut Vet.Med.J Vol 24, No. 47, Oct. 1990.

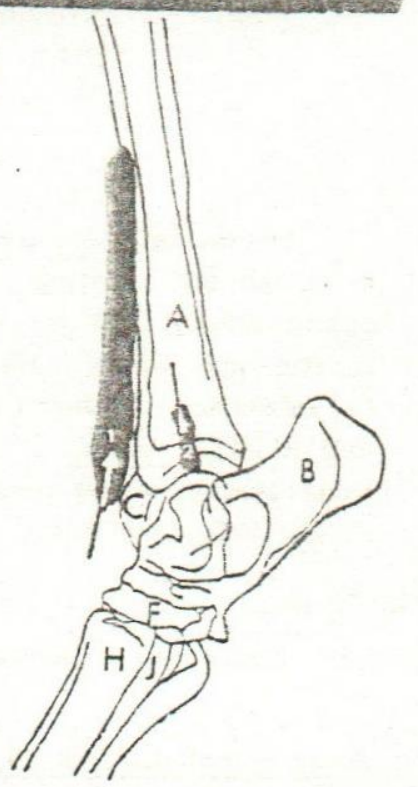

